\title{
Atypical mating in a scorpionfly without a notal organ
}

\author{
Wen Zhong ${ }^{1}$, Zi-Yi Qi ${ }^{1}$, Bao-Zhen Hua ${ }^{1,2}$ \\ ${ }^{1}$ State Key Laboratory of Crop Stress Biology for Arid Areas, Key Laboratory of Plant Protection Resources and \\ Pest Management, Ministry of Education, Entomological Museum, Northwest A \& F University, Yangling, Shaanxi \\ 712100, China \\ ${ }^{2}$ E-mail: huabzh@nwsuaf.edu.cn
}

Key words: Mecoptera, Panorpidae, Furcatopanorpa longihypovalva, mating behaviour, nuptial feeding, salivary glands, genitalia, functional morphology, copulation

\begin{abstract}
Firm coupling of genitalia is critical for copulation in most groups of insects. To counter female resistance that usually breaks off genital connection, male scorpionflies (Mecoptera: Panorpidae) usually provide nuptial gifts for the female and seize their mates with grasping devices. The notal organ, a modified clamp on tergum III of male scorpionflies, plays a significant role in seizing the female wings and helping maintain mating position during copulation. The mating behaviour remains unknown for the scorpionfly Furcatopanorpa longihypovalva (Hua and Cai, 2009) whose male lacks a notal organ. In this paper, we first attempt to study the mating behaviour of $F$. longihypovalva. The results show that the male provides liquid salivary secretion through a mouth-to-mouth mode for the female, and maintains copulation mainly by continuous provision of salivary secretion rather than by seizing the female with grasping devices. Thus the male copulates with the female in an atypical O-shaped position, with only their mouthparts and genitalia connected to each other. The salivary glands exhibit remarkable sexual dimorphism: short and bifurcated in the female, but well-developed and multi-furcated in the male. The extremely developed salivary glands of the male lay a structural foundation for the male to continuously provide liquid salivary secretion, and to help the male to mediate female resistance, being likely to serve as a compensation to his absence of the notal organ. We also investigated the functional morphology and copulatory mechanism of the male and female genitalia. The evolution of the atypical mating pattern of $F$. longihypovalva is putatively discussed as an adaptation in the context of sexual conflict.
\end{abstract}

\section{Contents}

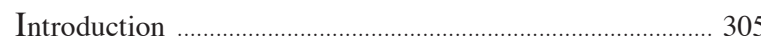

Material and methods ............................................................. 306

Adult collecting .................................................................... 306

Observation of the mating behaviour ............................... 306

Light and scanning electron microscopy .......................... 307

Morphology of the salivary glands .................................... 307

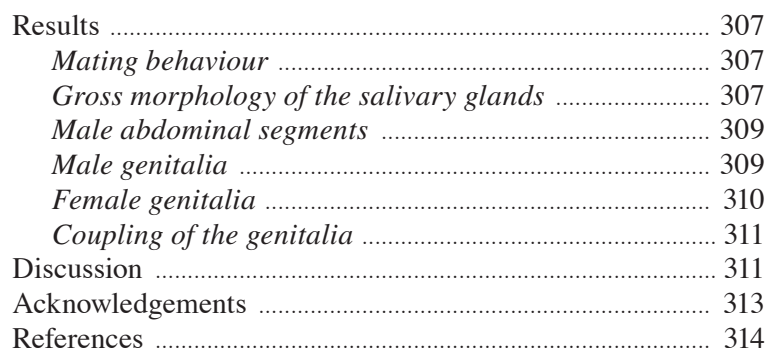

\section{Introduction}

The firm coupling of genitalia is critical for successful copulation of internally inseminating insects (Matthews and Matthews, 2010; Chapman, 2013). This process, however, is frequently interrupted or terminated by the female during copulation due to sexual conflict (Parker, 2006). To counter female resistance, males usually seize their mates with modified grasping devices, including claspers and other non-genital structures (Eberhard, 2010). In some species of insects, including scorpionflies (Mecoptera: Panorpidae), males provide edible gifts for the female to help obtain copulation and mediate female resistance (Gwynne, 2008).

Scorpionflies are intriguing insects for their males having a genital bulb that is enlarged and recurved antero-dorsally, superficially resembling the tail of a scorpion (Byers, 2002). The male of scorpionflies usually employs elaborate nuptial feeding behaviour to obtain copulation with the female. Males of some Panorpidae species bear well-developed salivary glands (Grell, 1938; Ma et al., 2011), thus they can secrete gelatinous salivary masses from their salivary glands as nuptial gifts to lure a female into copulation (Byers and Thornhill, 1983; Engqvist, 2007). If a male 


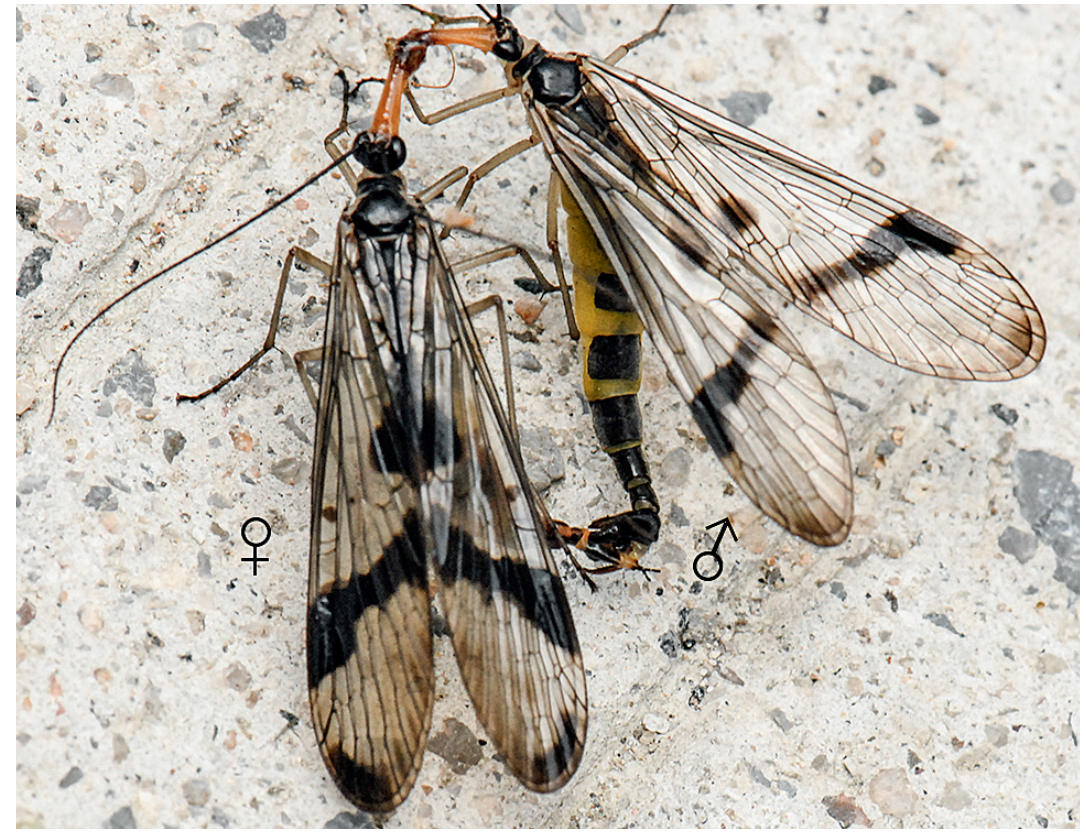

Fig. 1. Copulation of F. longihypovalva (close-up photograph). fails to offer salivary secretions, he alternatively provides a dead arthropod as a nuptial gift (Sauer et al., 1998; Engqvist and Sauer, 2003). In some cases, the male can obtain copulation by seizing the female with his claspers and other grasping devices, rather than by provisioning nuptial gifts, the so-called 'forced mating' or 'coercive copulation' (Thornhill, 1981; Engqvist and Sauer, 2003).

In both the gift- and non-gift-providing copulations, the notal organ (a modified abdominal clamp on tergum III) of male scorpionflies is utilized to seize the female to maintain mating position (Thornhill, 1981; Thornhill and Sauer, 1991). In many Panorpa species, males clamp the anterior margin of wings of the female with the notal organ (Mickoleit, 1971), which is regarded as helpful to prolong copulation, especially against female interests (Thornhill and Sauer, 1991). Kock et al. (2009) contend this view because the notal organ of male Panorpa vulgaris Imhoff and Labram, 1836 does not prolong copulation after the last nuptial gift has been delivered. In Neopanorpa longiprocessa Hua and Chou, 1997, the extremely developed notal organ is utilized to steadily seize the female's wings of one side, enabling the male to obtain copulation exclusively by seizing (Zhong and Hua, 2013b).

The notal organ not only plays a significant role in copulation (Thornhill and Sauer, 1991; Zhong et al., 2015), but also exhibits a great diversity among vari- ous species of Panorpidae (Issiki, 1933; Cheng, 1957). This important organ, however, is absent in the males of the scorpionfly Furcatopanorpa longihypovalva (Hua and Cai, 2009; Ma and Hua, 2011a). Here a question arises: how does such a male scorpionfly without a notal organ mate with the female? In this study, we investigate the mating behaviour and copulatory mechanism of $F$. longihypovalva to unravel the mating pattern of the scorpionfly without a notal organ.

\section{Material and methods}

\section{Adult collecting}

Adults of $F$. longihypovalva were collected along the

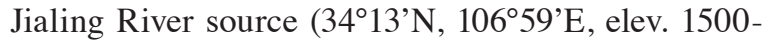
$1800 \mathrm{~m}$ ) in the Qinling Mountains, Shaanxi Province, China from the middle of May to the late June in 2013. All adults were caught at least a few days after eclosion because their bodies and wings were deeply pigmented.

\section{Observation of the mating behaviour}

The mating behaviour of $F$. longihypovalva was observed in the field, including the courtship, provisioning of nuptial gift, nuptial feeding, and copulation. 
Photographs of mating behaviour were taken with a Nikon D200 digital camera (Nikon, Tokyo, Japan).

\section{Light and scanning electron microscopy}

For light microscopy, live adults were fixed in Carnoy's solution for $12 \mathrm{~h}$ before being preserved in $75 \%$ ethanol. Specimens were dissected under a Nikon SMZ1500 stereoscopic zoom microscope (Nikon, Tokyo, Japan). Male and female genitalia dissected were macerated in cold 5\% sodium hydroxide solution for several hours and rinsed in distilled water. Micrographs were taken with a QImaging Retiga-2000R Fast 1394 Scientific CCD Camera (QImaging, Surrey, Canada) attached to a Nikon SMZ1500 microscope and were stacked with Syncroscopy Auto-Montage software (Syncroscopy, Cambridge, UK).

For scanning electron microscopy (SEM), ethanolpreserved specimens were dissected in $75 \%$ ethanol under a Nikon SMZ1500 microscope. The dissected genitalia and other genital components were dehydrated in a graded ethanol series after ultrasonic cleaning for $60 \mathrm{~s}$. Then the samples were dried with liquid carbon dioxide in a critical-point dryer, sputter-coated with gold, and examined in a Hitachi S-3400N scanning electron microscope (Hitachi, Tokyo, Japan).

\section{Morphology of the salivary glands}

A total of 33 individuals of $F$. longihypovalva (18 $\widehat{0} \widehat{0}$, 15 웅) were dissected to study the morphology of the salivary glands. The salivary glands were rapidly dissected in Ringer's solution, and then fixed in Carnoy's solution for $12 \mathrm{~h}$ before being preserved in $75 \%$ ethanol. In addition, to avoid low nutritional status that may impede the development of salivary glands of males (Engqvist and Sauer, 2001; Engels and Sauer, 2008), we supplied the field-caught $F$. longihypovalva adults with sufficient dead arthropods before dissection and morphological investigation.

\section{Results}

\section{Mating behaviour}

Seven pairs of $F$. longihypovalva were observed to mate in the daytime: six in the afternoon and one in the morning. All of these matings were accompanied with nuptial feeding behaviour. The male exclusively provided liquid salivary secretion for the female. The process of mating can be divided into two phases: courtship and copulation.

During courtship, the male vibrates his wings and swings his abdomen up-and-down rhythmically. Meanwhile, he releases sex pheromones from a pouchlike gland in the genital bulb to attract potential mates nearby (see Kock et al., 2007). Once the male lured a female, he terminates the olfactory releasing, and secretes a drop of liquid salivary secretion, which adheres to his mouthparts. Then he moves to the lateral side of the female, seizing her abdominal segment IX with his gonostyli when she attempts to feed on the salivary secretion. Thus the male and female form an O-shaped mating position: the male and female only contact to each other with their mouthparts and genitalia (Fig. 1).

During copulation, the male continuously transfers liquid salivary secretion to the female by a mouth-tomouth mode. The female usually cooperates with the male to maintain stable mating position when feeding on salivary secretion. After the male stopped providing salivary secretion, the female terminates copulation by lashing her abdomen to break off the genital coupling and then leaves the male.

\section{Gross morphology of the salivary glands}

The salivary glands are tubular labial glands, opening at the bottom of the salivarium between the labium and hypopharynx. They are similar to those of Panorpa species (see Grell, 1938). The salivary glands exhibit spectacular sexual dimorphism between the sexes: simply bifurcated and short in the female, but welldeveloped and multiple-furcated in the male (Fig. 2).

The salivary glands are undeveloped and short in the females, extending only to the prothorax, and consist of a salivary pump, a common salivary duct, and a pair of short secretory tubes. The salivary pump is swollen, and connects ventrally with the labium. The common salivary duct extends from the posterior end of the salivary pump, and runs along the rostrum, finally bifurcating to form a pair of secretory tubes (Fig. 2a).

The salivary glands are extremely well-developed in the males (Fig. 2b), usually extending to abdominal segment VI. The male salivary pump is very similar to that of the female. The common salivary duct extends posteriorly from the salivary pump along the rostrum of head and divides into two branches (salivary ducts) above the suboesophageal ganglion. Each of the branches expands into a sac and is subdivided 
into three secretory tubes subsequently, resulting in six secretory tubes in the thorax. The subsequent parts of the salivary glands twine around the gut and branch twice in a dichotomous way, eventually form- ing 24 distal secretory tubules that are convoluted in abdominal segments V and VI (Fig. 2b). In the male salivary glands, no prominent reservoirs were observed.

Fig. 2. Sexual dimorphism on salivary glands of $F$. longihypovalva (drawings). a, simple and undeveloped female salivary glands; b, well-developed male salivary glands. CSD, common salivary duct; DSTu, distal secretory tubule; SP, salivary pump; ST, secretory tube; STu, secretory tubule. Scale bar $=2.0 \mathrm{~mm}$.
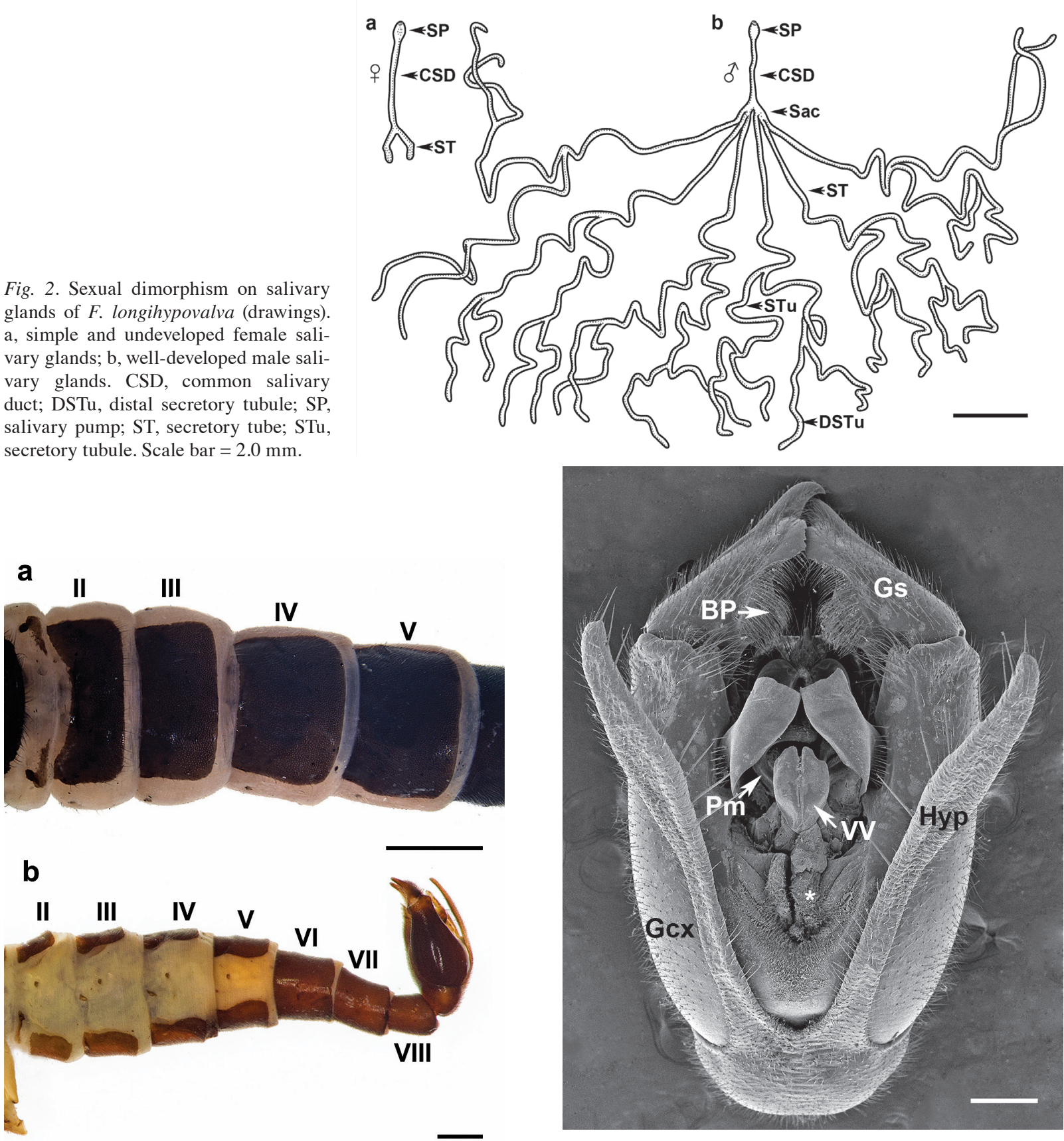

Fig. 3. Abdominal segments of male F. longihypovalva (microphotographs). a, dorsal view, scale bar $=0.5 \mathrm{~mm}$; $b$, lateral view, scale bar $=1.0 \mathrm{~mm}$.

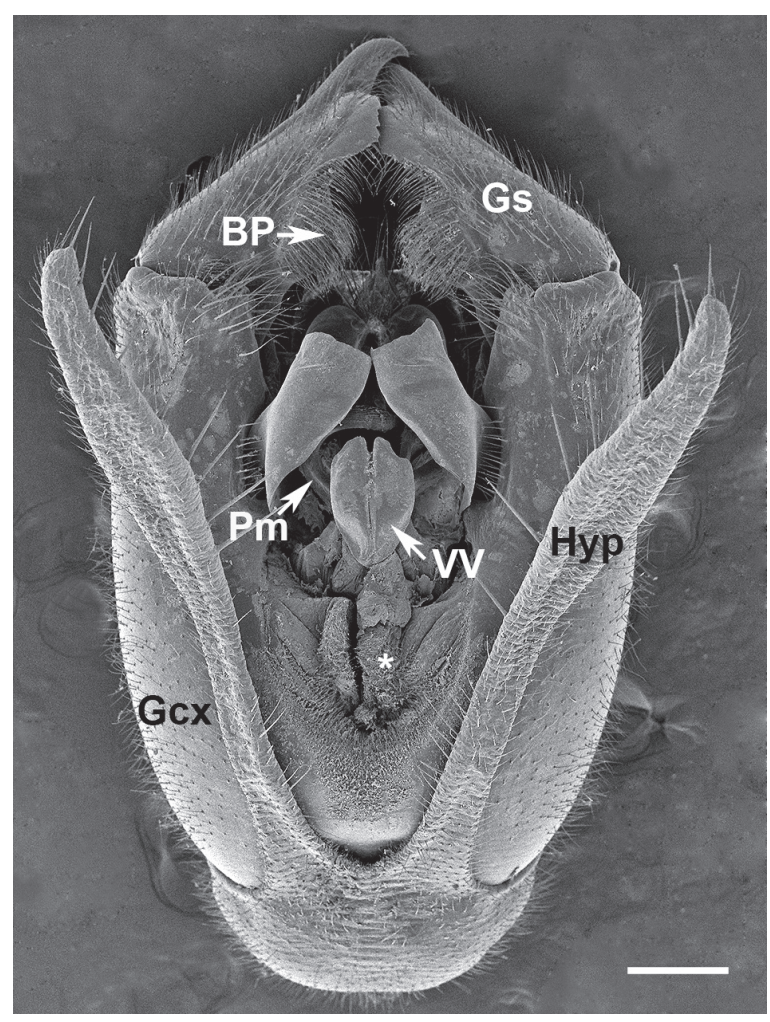

Fig. 4. Male genital bulb of $F$. longihypovalva, ventral view (SEMs). BP, basal process; Gcx, gonocoxite; Gs, gonostylus; Hyp, hypovalve; Pm, paramere; VV, ventral valve of aedeagus; *, pheromone gland. Scale bar $=300 \mu \mathrm{m}$. 


\section{Male abdominal segments}

The abdominal segments of males are simple in structure for terga II-V. It can be clearly seen that tergum III is devoid of a notal organ both from dorsal and lateral views (Fig. 3). Abdominal segments VI-VIII are greatly sclerotized into a ring. Tergum VI lacks any anal horn, and segments VII and VIII are thick and shortened, not constricted at the basal part (Fig. 3b).

\section{Male genitalia}

The male genitalia consist of the dorsal epandrium (tergum IX), the ventral hypandrium (sternum IX), the paired lateral gonopods, and the central aedeagal complex (Fig. 4).
The epandrium and hypandrium are fused at base, cupping the median aedeagal complex and the lateral gonopods. The epandrium is broad at the base and narrower toward the apex. The hypandrium is composed of a very short stalk and a pair of elongated hypovalves, each of which bears 8-10 thick bristles along the inner margin (Fig. 4).

The gonopod is composed of the basal gonocoxite and the distal gonostylus. The paired gonocoxites are fused together at the base, forming a deep U-shaped cavity, in which the aedeagal complex is inserted centrally (Fig. 4). The distal gonostyli serve as claspers during copulation. Each gonostylus has a broad basal process, which bears numerous setae and is serrate in distal margin. The median tooth is also broad and serrate in apical margin.
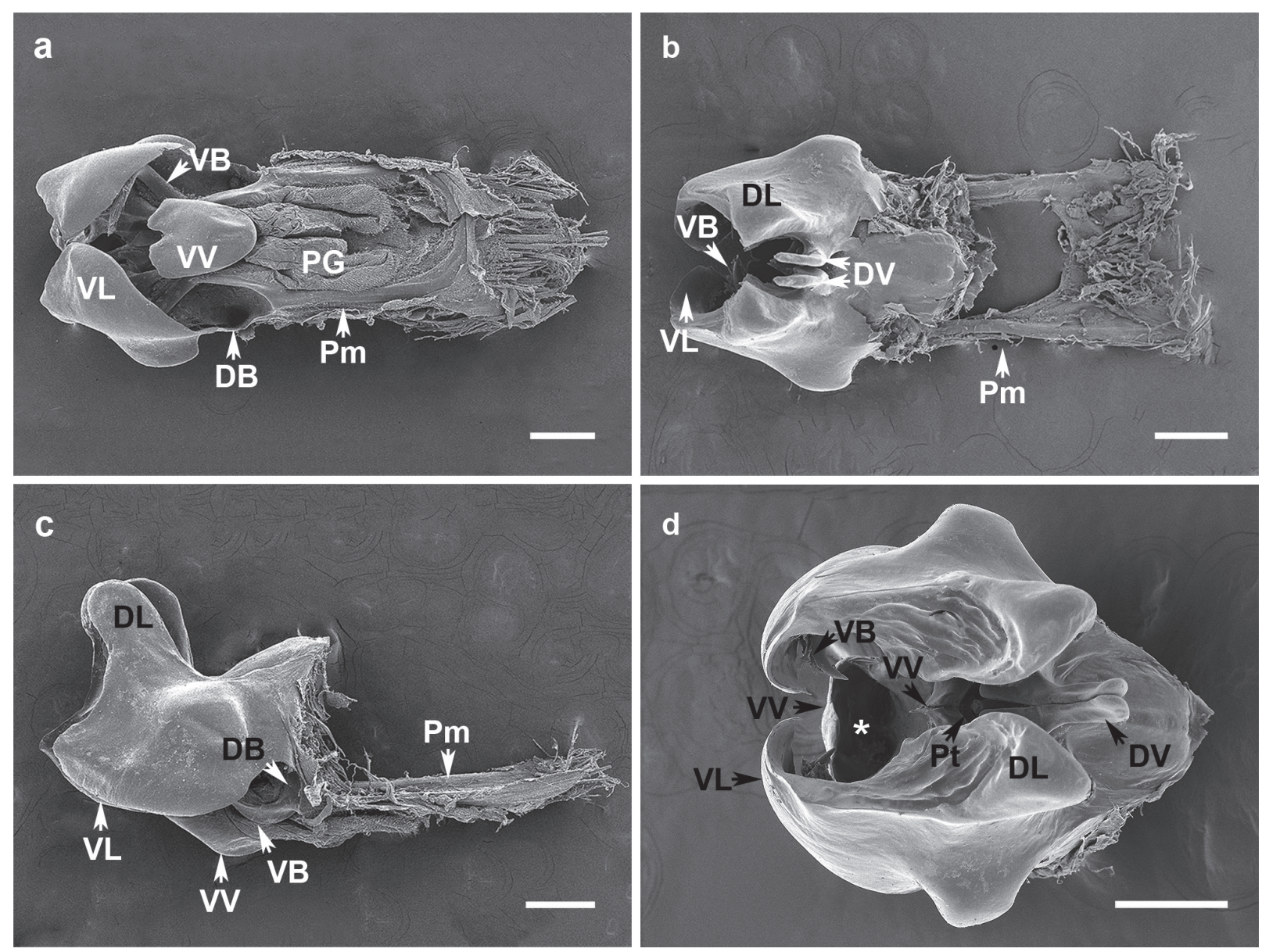

Fig. 5. Aedeagus and parameres of F. longihypovalva (SEMs). a, ventral view; b, dorsal view; c, lateral view; d, caudal view. DB, dorsal branch of paramere; DL, dorsal lobe of dorsal branch; DV, dorsal valve of aedeagus; PG, pheromone gland; Pm, paramere; Pt, phallotreme VB, ventral branch of paramere; VL, ventral lob of dorsal branch; VV, ventral valve of aedeagus; *, ventral pouch of aedeagus. Scale bars $=200 \mu \mathrm{m}$. 

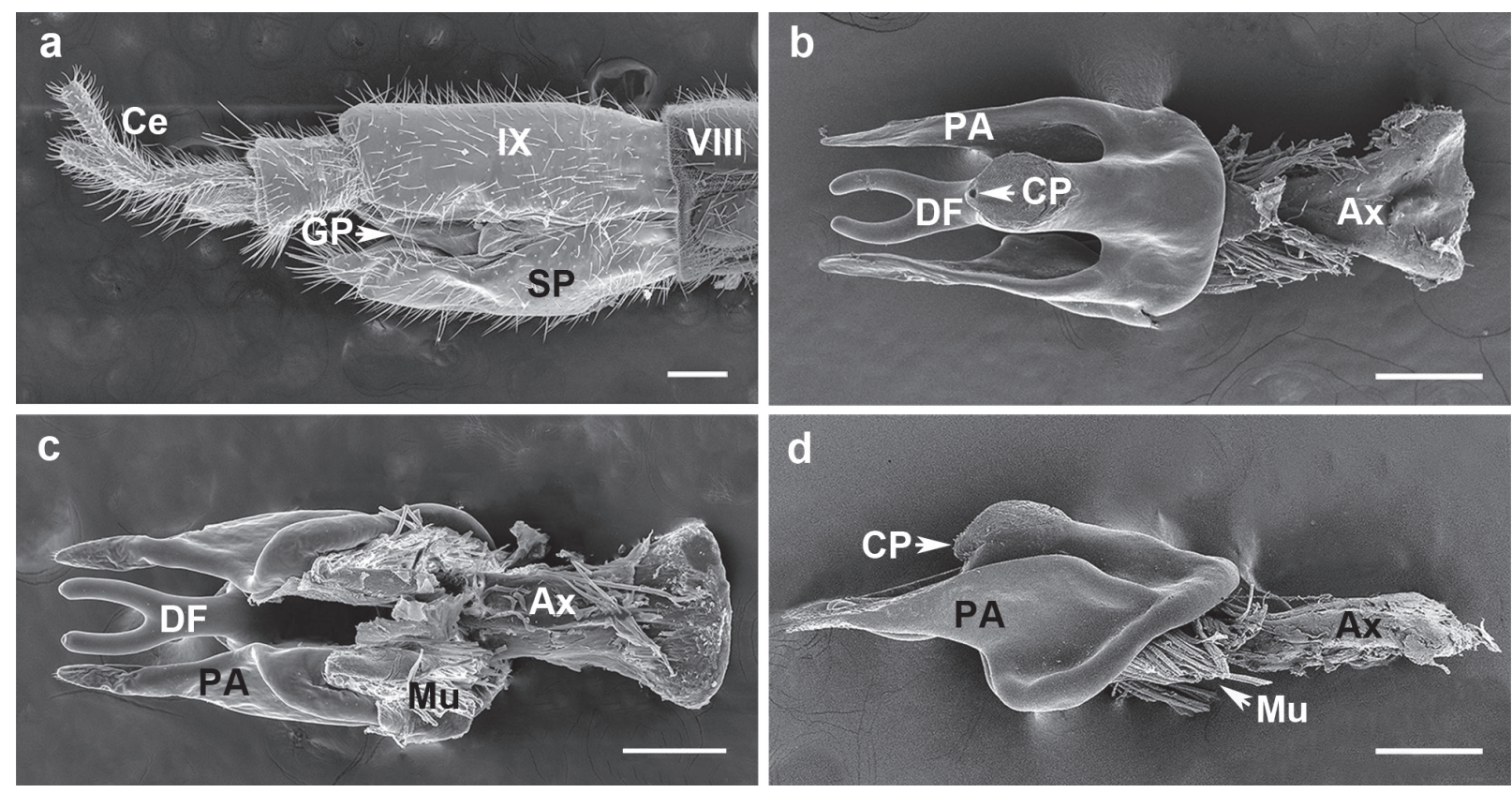

Fig. 6. Female genitalia of $F$. longihypovalva (SEMs). a, abdominal segments VIII-XI, lateral view; b-d, genital plate in ventral, dorsal, and lateral views. Ax, axis; Ce, cercus; CP, copulatory pore; DF, distal fork; GP, genital plate; Mu, muscles; PA, posterior arm; SP, subgenital plate; VIII and IX, tergum VIII and IX. Scale bars $=200 \mu \mathrm{m}$.

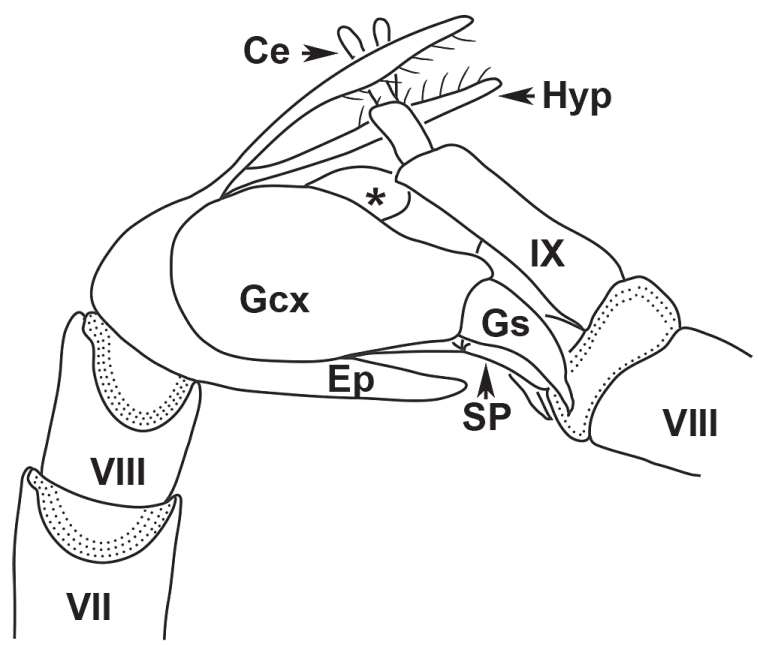

Fig. 7. Schematic drawing of the male grasping the abdomen of female with claspers and other grasping devices in copulation. Ce, cercus; Ep, epandrium; Gcx, gonocoxite; Gs, gonostylus; Hyp, hypovalve; SP, subgenital plate; VII, VIII, and IX, abdominal segment VII, VIII, and IX; *, everted swollen pheromone gland.

The aedeagal complex consists of an aedeagus and associated parameres. The aedeagus is composed of paired bilobed ventral and dorsal valves, basally fused with a pair of parameres (Figs 5a-c). The basal part of ventral valves produces caudally from the base of aedeagus, being mesally fused to form a deep cuculiform pouch (Figs 5a, c, d). The weakly-developed distal parts of ventral valves are mesally fused with each other and are concealed behind the dorsal branch of parameres in ventral view, surrounding the phallotreme with dorsal valves to form a concavity (Figs 5a, d). The dorsal valves are slender and narrower toward the apex, and separated from each other (Figs 5b, d).

The paramere is Y-shaped in ventro-lateral view: a single basal stalk bifurcates into a slender ventral branch and a well-developed dorsal branch. The basal stalk is fused with the opposite one at the base (Figs 5a, b). The dorsal branch consists of a mesally curved ventral lobe and a broad dorsal lobe (Fig. 5c). The ventral branch is slender, twists in an S-shape at the distal half, which is densely set with long setae and is concealed behind the ventral lobe of dorsal branch in ventral view (Figs 5a, d).

\section{Female genitalia}

The female genitalia are located on the ventral side of abdominal segment IX, and consist of a subgenital plate and a genital plate (Fig. 6a). The subgenital plate curves dorsally on posterior and lateral sides to form a shallow 
genital chamber above, in which the genital plate is situated. The genital plate consists of a main plate and a central axis. The broad main plate curves ventrally on lateral sides and extends caudally to form a pair of thick posterior arms. The axis passes through the main plate from dorsal to ventral side, and extends beyond the main plate slightly less than half its length. The posterior end of the axis protrudes beyond the main plate, with regular sculpturing on the ventral surface and a small copulatory pore (the orifice of the spermathecal duct) situated medially at the posterior apex. The main plate covers the posterior end of the axis from dorsal side, and bifurcates to form a pair of branches, the distal fork sensu Ma and Hua (2011a) (Figs 6b, c). In addition, bundles of longitudinal muscles attach to the anterior part of the axis as well as the dorsal surface of the main plate (Figs 6c, d). These muscles can stretch the genital plate out of the genital chamber, and allow the female copulatory pore to connect to the phallotreme of the male aedeagus.

\section{Coupling of the genitalia}

Stable coupling of the genitalia between the sexes ensures continuous sperm transfer, which is vital for a successful copulation. The structures of male genitalia can be divided into a central intromittent organ (the aedeagal complex in this context) and associated grasping devices. In scorpionflies the aedeagal complex is employed to connect to the orifice of the female spermathecal duct on the distal end of the genital plate to form a pathway for sperm transfer during copulation. The grasping devices include the gonostyli, epandrium, and hypovalves, and are used to grasp the particular part of the female body to ensure genital coupling. During copulation, the male seizes the basal abdominal segment IX of the female with his gonostyli, to open her genital chamber and to compel her to stretch out her genital plate. In addition, he uses his hypovalves to seize the abdominal segment IX or the cerci of the female, and keeps his pouch-like pheromone gland to swollen. This gland pushes up the abdominal segments X and XI of the female, thus opening the female genital chamber and enabling the phallotreme of the male aedeagus to contact to the copulatory pore of the female (Fig. 7).

\section{Discussion}

In the panorpid species whose mating behaviours have been studied to date, all the males use nuptial gifts and grasping devices or both to obtain copulation with the female (Engqvist and Sauer, 2003; Ma and Hua, 2011b). For both tactics, the male seizes the female with his notal organ to sustain mating position (Thornhill and Sauer, 1991). In our present research of mating behaviour in $F$. longihypovalva, whose male is devoid of a notal organ, we found a novel, atypical mating pattern in the Panorpidae for the first time. The male and female copulate in an O-shaped manner with their mouthparts and genitalia connected to each other (Fig. 1), remarkably different from the $\mathrm{V}$-shaped mating position in other scorpionflies studied (Ma and Hua, 2011b; Zhong and Hua, 2013b; Zhong et al., 2015).

Owing to the absence of the notal organs in male $F$. longihypovalva (Ma and Hua, 2011a), it is reasonable for the male not to seize the female with that kind of clamping device. Instead, the male mediates the female resistance mainly by providing liquid salivary secretion as a nuptial gift through a mouth-to-mouth feeding during copulation, resembling the trophallaxis of social termites and ants to a great extent (Matthews and Matthews, 2010). This nuptial feeding behaviour is greatly different from that of other Panorpidae species whose male adheres solid or gelatinous salivary secretions on a leaf surface for the female (Thornhill and Alcock, 1983; Zhong et al., 2015). Based on morphological studies by this investigation and others (Hua and Cai, 2009; Ma and Hua, 2011a), we assume that the formation of this atypical mating pattern is related to the well-developed salivary glands of the male and the genitalia of the male and female.

The greatly developed salivary glands of male $F$. longihypovalva provide a structural basis for this particular nuptial feeding behaviour, in which the male continuously provides liquid salivary secretion to the female. It is different from many other species of Panorpidae, whose males provide solid or gelatinous salivary secretion. This solid or gelatinous salivary secretion may be attributed to the male salivary glands of these species that include a dilated middle salivary reservoir to dehydrate liquid salivary secretion produced by the posterior secretory region (Ma et al., 2011). We assume that the dehydrated solidified salivary secretions can lead the female to spend more time to consume the nuptial gifts, thus prolonging the copulation duration. In male $F$. longihypovalva, the middle salivary reservoir of the salivary glands is reduced or even absent. Furthermore, the secretory region is extremely elongated and each secretory tube bifurcates twice to form 24 distal secretory tubules totally. The combination of developed secretory region and undeveloped 
middle dilated salivary reservoirs likely result in the failure of the male to dehydrate salivary secretion and to produce solidified salivary secretions. As a compensation, the developed secretory region of salivary glands is likely to greatly improve the male's ability to produce salivary secretion, enabling the male to continuously provide liquid salivary secretion to sustain copulation. This is one of the possible explanations why the male continuously provides liquid salivary secretion through a mouth-to-mouth feeding.

In scorpionflies nuptial-gift-providing mating is much more effective to copulation than coercive mating (Sauer et al., 1998; Kullmann and Sauer, 2009). On the other hand, seizing the female with his notal organ is likely not effective to mediate the female resistance or prolong copulation duration, as in Panorpa vulgaris (Kock et al., 2009). The modified complex female genitalia of $F$. longihypovalva may reduce the ability of the male to copulate against female interests. The distal fork of the female genital plate increases the difficulty of coercive copulation by obstructing the coupling of genitalia. Based on morphological investigation, we assume that a male has to accurately locate the distal fork of the female genital plate into the ventral pouch of his aedeagus, thus he could correctly connect his phallotreme with the female copulatory pore to ensure sperm transfer. The female, however, can still easily break off the coupling of genitalia to terminate the copulation through retreating her genital plate. In this case, seizing the female only with his notal organ or other clasping devices can have little help in obtaining copulation, which needs cooperation between the male and female. Thus we assume that in male $F$. longihypovalva, continuous provisioning of salivary secretion as nuptial gifts is likely used to 'buy' the female's cooperation to obtain and sustain copulation. The salivary glands, notal organ, and genitalia of male and female likely play essential roles in the formation of the mating behaviour of $F$. longihypovalva. We summarized the morphological differences of these structures between $F$. longihypovalva and the 'typical' panorpids as exemplified by Panorpa dubia Chou in Table 1.

Sexual conflict is caused by divergent reproductive, evolutionary, and genetic interests between the sexes (Chapman et al., 2003; Parker, 2006), and may also contribute to the formation of this atypical mating behaviour in F. longihypovalva. In the mating of scorpionflies, sexual conflict is mainly expressed as the fierce contest on control over nuptial gifts (Engqvist, 2011). Because providing salivary masses requires a huge nutrient investment for the male (Sauer et al., 1998; Engels and Sauer, 2006), it is the male's interest to avoid wasting his salivary secretion so as to maximize the number of his mates and guarantee his mating success rate (Zhong et al., 2015). On the other hand, the female struggles to consume maximum salivary masses, probably impeding subsequent matings of the male (Engqvist, 2009). The males of F. longihypovalva have successfully solved this problem by con-

\begin{tabular}{|c|c|c|}
\hline & F. longihypovalva & 'Typical' panorpid Panorpa dubia Chou \\
\hline Male notal organ & lacking (Fig. 3a) & $\begin{array}{l}\text { moderately- or } \\
\text { well-developed }\end{array}$ \\
\hline Male salivary glands & $\begin{array}{l}\text { secretory tubes } \\
\text { bifurcated twice; , } \\
\text { reservoirs undeveloped } \\
\text { not expanded (Fig. 2b) }\end{array}$ & $\begin{array}{l}\text { secretory tubes } \\
\text { bifurcated once or not; } \\
\text { reservoirs developed, } \\
\text { usually expanded }\end{array}$ \\
\hline Male aedeagus & $\begin{array}{l}\text { with a ventral pouch } \\
\text { (Figs } 5 a, d)\end{array}$ & without a ventral pouch \\
\hline Female genital plate & $\begin{array}{l}\text { with a distal fork } \\
\text { (Fig. 6b) }\end{array}$ & without a distal fork \\
\hline
\end{tabular}

Table 1. Morphological differences between $F$. longihypovalva and 'typical' panorpids. with a distal fork (Fig. 6b) secretory tubes reservoirs developed, usually expanded

without a ventral pouch 
tinuously providing liquid salivary secretion to the female through mouth-to-mouth feeding during copulation. It enables the male to terminate provisioning nuptial gift immediately if the female terminates copulation, thus avoiding wasting salivary secretion in fruitless courtship and failed matings that are too short to transfer enough sperm. Furthermore, continuous provisioning of liquid salivary secretion invalidates snatching of nuptial gifts by the female or conspecific males.

Based on the developmental degrees of the male notal organ and salivary glands, the nuptial feeding behaviour of scorpionflies can be broadly divided into four types: solid-salivary-mass-dominant mating, preygift-only mating, coercive copulation, and liquid-salivary-only mating. In the first type of mating, males of many Panorpa species mainly provide salivary secretions to obtain copulation, sporadically employing coercive copulation. These species bear a moderately developed notal organ (Zhong and Hua, 2013a: Fig. $1 \mathrm{~F}$ ), and have developed salivary glands (Ma et al. 2011: Fig. 1), which are able to produce enough salivary secretions as nuptial gifts (Grell, 1938; Engqvist, 2007; Kock et al., 2009; Zhong et al., 2015). In the second type, males of some Panorpa species, as exemplified in P. liui Hua and Chou, 1997, P. nuptialis Gerstaecker, 1863, and P. japonica Thunberg, 1784, have a moderately developed notal organ and reduced or weakly-developed salivary glands ( $\mathrm{Ma}$ and Hua, 2011b: Figs 1,2). They can only provide dead arthropods as nuptial gifts to the female or employ a coercive copulation since they are unable to produce enough salivary masses (Byers, 1963; Thornhill, 1992; Ma and Hua, 2011b). In the third type, males of Neopanorpa longiprocessa exclusively employ coercive copulation and provide no nuptial gifts. They bear a greatly developed notal organ (Zhong and Hua, 2013b: Figs 1, 3) and moderately developed salivary glands (Ma et al. 2011: Figs 2F, G), which are also unable to produce enough salivary secretions (Zhong and Hua, 2013b). In $F$. longihypovalva, owing to the absence of a notal organ, the male exclusively relies on a unique liquidsalivary-only nuptial feeding through a mouth-tomouth transfer. Concomitantly, the male has extremely developed salivary glands to provide sufficient liquid salivary secretion to the female during copulation. This atypical mating behaviour of $F$. longihypovalva provides additional new evidence to support our recently proposed hypothesis that the developmental degree of salivary glands is negatively correlated with the notal organ in male scorpionflies (Zhong and Hua, 2013b). This hypothesis may help understand the formation and diversity of mating patterns of Panorpidae species in morphological aspect.

From a phylogenetic point of view, $F$. longihypovalva may evolve early in Panorpidae based on morphological characters (Ma and Hua, 2011a; Ma et al., 2012). The morphological phylogenetic analysis indicates that the genus Furcatopanorpa forms a sister taxon to all the other genera in Panorpidae (Ma et al., 2012). This probably explains why the mating behaviour of $F$. longihypovalva differs markedly from that of other panorpids in phylogenetic aspect. The recent molecular phylogenetic study, however, shows that $F$. longihypovalva forms a sister-group relationship with Panorpa liui based on mitochondrial and nuclear gene sequences (Hu et al., 2015). From a behavioural point of view, this conclusion seems strange because the mating behaviours of $F$. longihypovalva and $P$. liui differ remarkably from each other as mentioned above. Further research is needed to solve this contradiction problem.

A similar mating pattern is also present in the mecopteran family Choristidae (Tillyard, 1926; Riek, 1970). According to R. Thornhill (personal communication), the males of Chorista australis Klug, 1836 in New South Wales, Australia, also lack a notal organ. The male and female $C$. australis form the $\mathrm{O}$-shaped mating position and contact each other with mouthparts during copulation. This behaviour is regarded as a transfer of liquid salivary secretion from the male to the female through a mouth-to-mouth mode. In addition, Thornhill's observation shows that male C. australis does not provide salivary masses or putting salivary secretions on the substrate as nuptial gifts as in most other panorpids (R. Thornhill, personal communication). Since Choristidae is the sister group of Panorpoidea (Panorpidae + Panorpodidae) (Willmann, 1987), the absence of a notal organ and the O-shaped mating behaviour are very likely plesiomorphic characters in scorpionflies, suggesting that mating behaviour is closely related with morphology and may play a significant role in evolutionary and phylogenetic analyses in Mecoptera.

\section{Acknowledgements}

We are indebted to Guo Ding for assistance in insect collection and observation. We are grateful to Randy Thornhill for kindly sharing unpublished information on the mating behaviour of Chorista australis. We appreciate Lu Jiang for providing information on the morphology and biology of scorpionflies. We also 
thank Randy Thornhill and another anonymous reviewer for valuable comments and suggestions on the revision of the manuscript. This research was funded by the National Natural Science Foundation of China (grant no. 31172125) and the China Postdoctoral Science Foundation (grant no. 2013M542389).

\section{References}

Byers GW. 1963. The life history of Panorpa nuptialis (Mecoptera: Panorpidae). Annals of the Entomological Society of America 56: 142-149. doi: 10.1093/aesa/56.2.142

Byers GW. 2002. Scorpionflies, hangingflies, and other Mecoptera. Kansas School Naturalist 48: 3-15.

Byers GW, Thornhill R. 1983. Biology of the Mecoptera. Annual Review of Entomology 28: 203-228. doi: 10.1146/annurev.en.28.010183.001223

Chapman RF. 2013. The insects: structure and function. 5th ed. Cambridge: Cambridge University Press.

Chapman T, Arnqvist G, Bangham J, Rowe L. 2003. Sexual conflict. Trends in Ecology and Evolution 18: 41-47. doi: 10.1016/s0169-5347(02)00004-6

Cheng FY. 1957. Revision of the Chinese Mecoptera. Bulletin of the Museum of Comparative Zoology 116: 1-118.

Eberhard WG. 2010. Evolution of genitalia: theories, evidence, and new directions. Genetica 138: 5-18. doi: 10.1007/s10709 -009-9358-y

Engels S, Sauer KP. 2006. Resource-dependent nuptial feeding in Panorpa vulgaris: an honest signal for male quality. Behavioral Ecology 17: 628-632. doi: 10.1093/beheco/ark007

Engels S, Sauer KP. 2008. A secondary sex trait under construction: age- and nutrition-related salivary gland development in a scorpionfly (Insecta: Mecoptera). Journal of Zoological Systematics and Evolutionary Research 46: 133136. doi: 10.1111/j.1439-0469.2007.00438.x

Engqvist L. 2007. Sex, food and conflicts: nutrition dependent nuptial feeding and pre-mating struggles in scorpionflies. Behavioral Ecology and Sociobiology 61: 703-710. doi: 10.1007/s00265-006-0300-3

Engqvist L. 2009. Should I stay or should I go? Condition- and status-dependent courtship decisions in the scorpionfly Panorpa cognata. Animal Behaviour 78: 491-497. doi: 10.1016/j.anbehav.2009.05.021

Engqvist L. 2011. Male attractiveness is negatively genetically associated with investment in copulations. Behavioral Ecology 22: 345-349. doi: 10.1093/beheco/arq211

Engqvist L, Sauer KP. 2001. Strategic male mating effort and cryptic male choice in a scorpionfly. Proceedings of the Royal Society B: Biological Sciences 268: 729-735. doi: 10.1098/rspb.2000.1423

Engqvist L, Sauer KP. 2003. Influence of nutrition on courtship and mating in the scorpionfly Panorpa cognata (Mecoptera, insecta). Ethology 109: 911-928. doi: 10.1046/j.1439-0310. 2003.00937.x

Grell KG. 1938. Der Darmtraktus von Panorpa communis L. und seine Anhänge bei Larve und Imago. Zoologische Jahrbücher. Abteilung für Anatomie und Ontogenie der Tiere 64: 1-86.

Gwynne DT. 2008. Sexual conflict over nuptial gifts in insects. Annual Review of Entomology 53: 83-101. doi: 10.1146/annurev.ento.53.103106.093423
Hu GL, Yan G, Xu H, Hua BZ. 2015. Molecular phylogeny of Panorpidae (Insecta: Mecoptera) based on mitochondrial and nuclear genes. Molecular Phylogenetics and Evolution 85: 22-31. doi: 10.1016/j.ympev.2015.01.009

Hua BZ, Cai LJ. 2009. A new species of the genus Panorpa (Mecoptera: Panorpidae) from China with notes on its biology. Journal of Natural History 43: 545-552. doi: 10.1080/ 00222930802610519

Issiki S. 1933. Morphological studies on the Panorpidae of Japan and adjoining countries and comparison with American and European forms. Japanese Journal of Zoology 4: 315416.

Kock D, Engels S, Fritsche C, Sauer KP. 2009. Sexual coercion in Panorpa scorpionflies? - The function of the notal organ reconsidered. Behavioral Ecology 20: 639-643. doi: 10.1093/ beheco/arp043

Kock D, Ruther J, Sauer KP. 2007. A male sex pheromone in a scorpionfly. Journal of Chemical Ecology 33: 1249-1256. doi: 10.1007/s10886-007-9304-3

Kullmann H, Sauer KP. 2009. Mating tactic dependent sperm transfer rates in Panorpa similis (Mecoptera; Panorpidae): a case of female control? Ecological Entomology 34: 153-157. doi: 10.1111/j.1365-2311.2008.01039.x

Ma N, Hua BZ. 2011a. Furcatopanorpa, a new genus of Panorpidae (Mecoptera) from China. Journal of Natural History 45: 2251-2261. doi: 10.1080/00222933.2011.595517

Ma N, Hua BZ. 2011b. Structural evidence why males of Panorpa liui offer prey rather than salivary mass as their nuptial gift. Acta Zoologica 92: 398-403. doi: 10.1111/j.1463-6395. 2010.00474.x

Ma N, Liu SY, Hua BZ. 2011. Morphological diversity of male salivary glands in Panorpidae (Mecoptera). European Journal of Entomology 108: 493-499. doi: 10.14411/eje. 2011.064

Ma N, Zhong W, Gao QH, Hua BZ. 2012. Female genital plate diversity and phylogenetic analyses of East Asian Panorpidae (Mecoptera). Systematics and Biodiversity 10: 159-178. doi: $10.1080 / 14772000.2012 .683459$

Matthews RW, Matthews JR. 2010. Insect behavior. 2nd ed. London: Springer. doi: 10.1007/978-90-481-2389-6

Mickoleit G. 1971. Zur phylogenetischen und funktionellen Bedeutung der sogenannten Notalorgane der Mecoptera (Insecta, Mecoptera). Zeitschrift für Morphologie der Tiere 69: 1-8. doi: 10.1007/BF00294385

Parker GA. 2006. Sexual conflict over mating and fertilization: an overview. Philosophical Transactions of the Royal Society B: Biological Sciences 361: 235-259. doi: 10.1098/rstb. 2005.1785

Riek EF. 1970. Mecoptera. Pp. 636-646 in: The Insects of Australia, ed.CSIRO, Canberra, Carlton: Melbourne University Press.

Sauer KP, Lubjuhn T, Sindern J, Kullmann H, Kurtz J, Epplen C, Epplen JT. 1998. Mating system and sexual selection in the scorpionfly Panorpa vulgaris (Mecoptera: Panorpidae). Naturwissenschaften 85: 219-228. doi: 10.1007/s0011400 50487

Thornhill R. 1981. Panorpa (Mecoptera: Panorpidae) scorpionflies: systems for understanding resource-defense polygyny and alternative male reproductive efforts. Annual Review of Ecology and Systematics 12: 355-386. doi: 10.1146/annurev. es.12.110181.002035 
Thornhill R. 1992. Fluctuating asymmetry and the mating system of the Japanese scorpionfly, Panorpa japonica. Animal Behaviour 44: 867-879. doi: 10.1016/S0003-3472(05) 80583-4

Thornhill R, Alcock J. 1983. Evolution of insect mating systems. Massachusetts: Harvard University Press. 544 pp.

Thornhill R, Sauer KP. 1991. The notal organ of the scorpionfly (Panorpa vulgaris): an adaptation to coerce mating duration. Behavioral Ecology 2: 156-164. doi: 10.1093/beheco/ 2.2.156

Tillyard RJ. 1926. The Insects of Australia and New Zealand. Sydney: Angus and Robertson.

Willmann R. 1987. The phylogenetic system of the Mecoptera. Systematic Entomology 12: 519-524. doi: 10.1111/j.13653113.1987.tb00222.x

Zhong W, Ding G, Hua BZ. 2015. The role of male's anal horns in copulation of a scorpionfly. Journal of Zoology 295: 170177. doi: $10.1111 /$ jzo. 12194

Zhong W, Hua BZ. 2013a. Dicerapanorpa, a new genus of East Asian Panorpidae (Insecta: Mecoptera: Panorpidae) with descriptions of two new species. Journal of Natural History 47: 1019-1046. doi: 10.1080/00222933.2012.752540

Zhong W, Hua BZ. 2013b. Mating behaviour and copulatory mechanism in the scorpionfly Neopanorpa longiprocessa (Mecoptera: Panorpidae). PLoS ONE 8: e74781. doi: 10.1371/ journal.pone.0074781

Received: 21 January 2015

Revised and accepted: 7 July 2015

Published online: 12 November 2015

Editor: H. de Jong 